\title{
Rare lichen planus
}

INSERM

\section{Source}

INSERM. (1999). Orphanet: an online rare disease and orphan drug data base. Rare lichen planus. ORPHA:254367

Lichen planus (LP) is a common inflammatory dermatosis characterized by the development of pruritic violaceous papules or plaques on mucocutaneous surfaces. Eruptions can involve the face, neck, limbs, back, genitalia, tongue, buccal mucosa, nails, and scalp. LP comprises rare variants affecting the skin and the mucosa. Rare cutaneous LP includes linear LP (referring to blaschkoid and zosteriform distributions of lichenoid lesions), actinic LP, annular LP, atrophic LP, annular atrophic LP, lichen planopilaris (comprising Graham Little-Piccardi-Lassueur syndrome and frontal fibrosing alopecia), lichen planus pigmentosus, and lichen planus pemphigoides (see these terms). Rare mucosal LP includes vulvovag inal ging ival syndrome and LP sialadenitis (see these terms). 